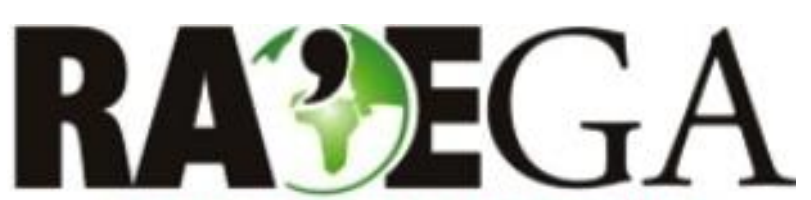

O ESPAÇO GEOGRÁFICO EM ANÁLISE

\title{
ANÁLISE DAS PRECIPITAÇÕES EM TRECHO DO MÉDIO CURSO DA BACIA HIDROGRÁFICA DO RIO POTI (PIAUÍ), A PARTIR DO ÍNDICE DE ANOMALIA DE CHUVA (IAC)
}

\section{ANALYSIS OF PRECIPITATIONS IN THE MIDDLE OF THE POTI RIVER HYDROGRAPHIC BASIN (PIAUÍ), FROM THE RAIN ANOMALY INDEX (RAI)}

\author{
Karoliny Fontenele Cerqueira ${ }^{1}$, Francílio de Amorim dos Santos ${ }^{2}$, Cláudia Maria Sabóia Aquino ${ }^{3}$
}

\section{RESUMO}

A preocupação com o múltiplo uso da água vem acentuando-se, principalmente, no Nordeste semiárido, onde diversos fatores aumentam a fragilidade natural. Dessa forma, tornou-se oportuno analisar o comportamento das precipitações em trecho do médio curso da Bacia Hidrográfica do rio Poti (Piauí), Nordeste do Brasil, a partir de estatística descritiva, Geoestatística e do Índice de Anomalia da Chuva (IAC). Para isso, foram utilizados dados de 5 (cinco) postos pluviométricos da Agência Nacional de Águas (ANA) aliados ao uso dos softwares BioEstat e do pacote de programas USUAIS. Através dos resultados, constatou-se grande variabilidade das precipitações no que tange ao desvio em relação à média, com a quadra chuvosa concentrada nos meses de janeiro a abril. Não obstante, pode-se identificar que a maior parte do ano apresenta precipitações abaixo da média. Através do IAC, constatou-se que a série histórica apresenta predominância de anos secos, que totalizou 35,9\% dos anos analisados, possuindo uma maior tendência a desenvolver anos extremamente secos, ao passo que sua ocorrência pode ser relacionada à presença de fenômenos El niño e à fase positiva do dipolo do Atlântico. Isso acaba por incitar, assim, maiores estudos para o aprofundamento dos impactos dessa variabilidade sobre a paisagem e as atividades humanas na área estudada.

Palavras-chave: Recurso Hídrico; Chuvas; Estatística Descritiva; Índice.

\section{ABSTRACT}

The concern with the multiple use of water has been accentuated mainly in the semi-arid Northeast of Brazil, where several factors increase the natural fragility. Thus, it was opportune to analyze the rainfall behavior in the middle course of the Poti River Basin (state of Piauí), Northeast Brazil, from descriptive statistics, Geostatistics and the Rainfall Anomaly Index (RAI). For this, data from 6 (six) pluviometric stations of the National Water Agency (AWA) were used in conjunction with the use of BioEstat software and the USUAIS program package. The results showed a great variability of rainfall in relation to the deviation from the average, with rainy season concentrated in the months of January to April. While it can be seen that most of the year has below-average rainfall. Through the IAC, it was verified that the historical series shows a predominance of dry years, which totalized $35.9 \%$ of the analyzed years, possessing a greater tendency to develop extremely dry years, whereas its occurrence can be related to the presence of phenomena El niño and the positive phase of The Atlantic dipole. In this way, we stimulate further studies to deepen impacts of this variability on the landscape and human activities in the studied area.

Key-words: Water Resources; Rainfall; Descriptive Statistics; Index.

Recebido em: 03/03/2017

Aceito em: 27/10/2017

\footnotetext{
${ }^{1}$ Faculdade Integral Diferencial, Teresina/PI, e-mail: karolinyfoncer@gmail.com.

2 Instituto Federal do Piaui, Piripiri/PI, e-mail:francilio.amorim@ifpi.edu.br.

3 Universidade Federal do Piauí, Teresina/PI, e-mail: cmsaboia@gmail.com.
} 


\section{ANÁLISE DAS PRECIPITAÇÕES EM TRECHO DO MÉDIO CURSO DA BACIA HIDROGRÁFICA DO RIO POTI (PIAUÍ), A PARTIR DO ÍNDICE DE ANOMALIA DE CHUVA (IAC)}

\section{INTRODUÇÃO}

Os totais de precipitação estão altamente ligados às condições climáticas locais, tendo influência direta sobre as atividades humanas realizadas em determinada área, tais como a agricultura, a pecuária, dentre outras. Em termos gerais, o conhecimento dos níveis de precipitação possibilita melhorar a produtividade das atividades econômicas, bem como o uso da água para múltiplas atividades.

Nesse contexto, o Nordeste do Brasil (NEB) apresenta uma problematização quanto a essas condições, visto que apresente irregularidade pluviométrica indicada, principalmente, pela duração e intensidade das precipitações. Diante disso, grande parte do NEB está submetida a intensas e frequentes secas, que ocasionam fenômenos como o êxodo rural, enfraquecimento da economia local e fragilização do solo, resultando em diversos problemas para a região (SILVA et al., 2009).

Assim, levando em conta os problemas referentes à disponibilidade hídrica do NEB, torna-se necessária e adequada a realização de uma análise das precipitações no trecho do médio curso da Bacia Hidrográfica do rio Poti, situada no Nordeste do estado do Piauí. Diga-se, ainda, que a região se encontra em local com vegetação já fragilizada e com tipologias de solo vulnerável à erosão, ratificando a importância da análise pluviométrica no referido trecho.

A área em estudo apresenta características que a colocam como área suscetível a processos erosivos, notadamente no que concerne a seus componentes climáticos e pedológicos. Apresenta também significativo volume pluviométrico concentrado em 4 a 5 meses, que caem sobre solos jovens e pouco desenvolvidos que, por sua vez, são recobertos por vegetação com baixo potencial de proteção (SANTOS, 2015).

Para a operacionalização do presente estudo, foram utilizados dados de 5 (cinco) postos pluviométricos de uma série histórica de 1963 a 2001, obtidos junto à Agência Nacional de Águas (ANA, 2016), em área localizada entre os municípios de Juazeiro do Piauí e Castelo do
Piauí. Deve-se destacar que o recorte temporal deu-se notadamente devido à falta de dados para os postos pluviométricos além do ano de 2001.

Os referidos dados passaram pela correção de falhas, realizada por meio do pacote de programas USUAIS, de técnica de Ponderação Regional e utilização dos seguintes softwares: BioEstat, versão 5.0, para a realização da estatística descritiva; e QuantumGIS (QGIS), versão 2.18, para espacialização dos dados pluviométricos.

Atualmente, diversos índices têm sido utilizados em pesquisas para conhecimento das anomalias pluviométricas, tendo a possibilidade de identificar os anos secos e chuvosos no Nordeste do Brasil (NEB). Nesse contexto, destaca-se o Índice de Anomalia das Chuvas (IAC), aqui empregado, utilizado para realização dos seguintes estudos:

Utilizando o IAC, Araújo et al. (2008) desenvolveram uma análise da variabilidade climática e sua influência sobre a precipitação, além de analisar a variabilidade espaçotemporal das chuvas para bacia do rio Paraíba. Por meio do IAC, foram encontradas semelhanças entre os padrões de outras bacias, na alternância de anos secos e chuvosos.

Também por uso do IAC e da análise de ondeleta, Silva et al. (2009) realizaram uma análise na bacia hidrográfica do rio Mundaú, no estado de Alagoas. A pesquisa foi desenvolvida com o intuito de verificar quais escalas exercem uma influência sobre a variabilidade pluviométrica da região, obtendo o resultado de que a variabilidade da precipitação é definida por multi-escalas temporais, localizadas em certos intervalos de tempo.

Ainda analisando a bacia hidrográfica do rio Mundaú, Silva et al. (2010) utilizaram dados de precipitação das três regiões da bacia, localizada nos estados de Alagoas e Pernambuco. A realização do estudo foi desenvolvida por meio do IAC, demonstrando que há variações temporais distintas na região, exceto por anos secos no início do período utilizado, entre 1955 e 1991. 


\section{ANÁLISE DAS PRECIPITAÇÕES EM TRECHO DO MÉDIO CURSO DA BACIA HIDROGRÁFICA DO RIO POTI (PIAUÍ), A PARTIR DO ÍNDICE DE ANOMALIA DE CHUVA (IAC)}

Frente a importância do conhecimento sobre as variações pluviométricas, o estudo teve como objetivo analisar o comportamento das precipitações em trecho do médio curso da Bacia Hidrográfica do rio Poti, no Nordeste do estado do Piauí, a partir de estatística descritiva, Geoestatística e do Índice de Anomalia da Chuva (IAC).

\section{MATERIAIS E MÉTODOS}

2.1. Localização da área em estudo e os sistemas atuantes no Norte do Nordeste do Brasil

A área estudada, que corresponde a um trecho do médio curso da Bacia Hidrográfica do rio Poti, apresenta $1.466,7 \mathrm{~km}^{2}$ e perímetro de $239,1 \mathrm{~km}^{2}$. O trecho em questão localiza-se entre os municípios de Juazeiro do Piauí e Castelo do Piauí (Figura 1), ambos situados no Território de Desenvolvimento dos Carnaubais (PIAUÍ, 2006), no setor Nordeste do referido estado.

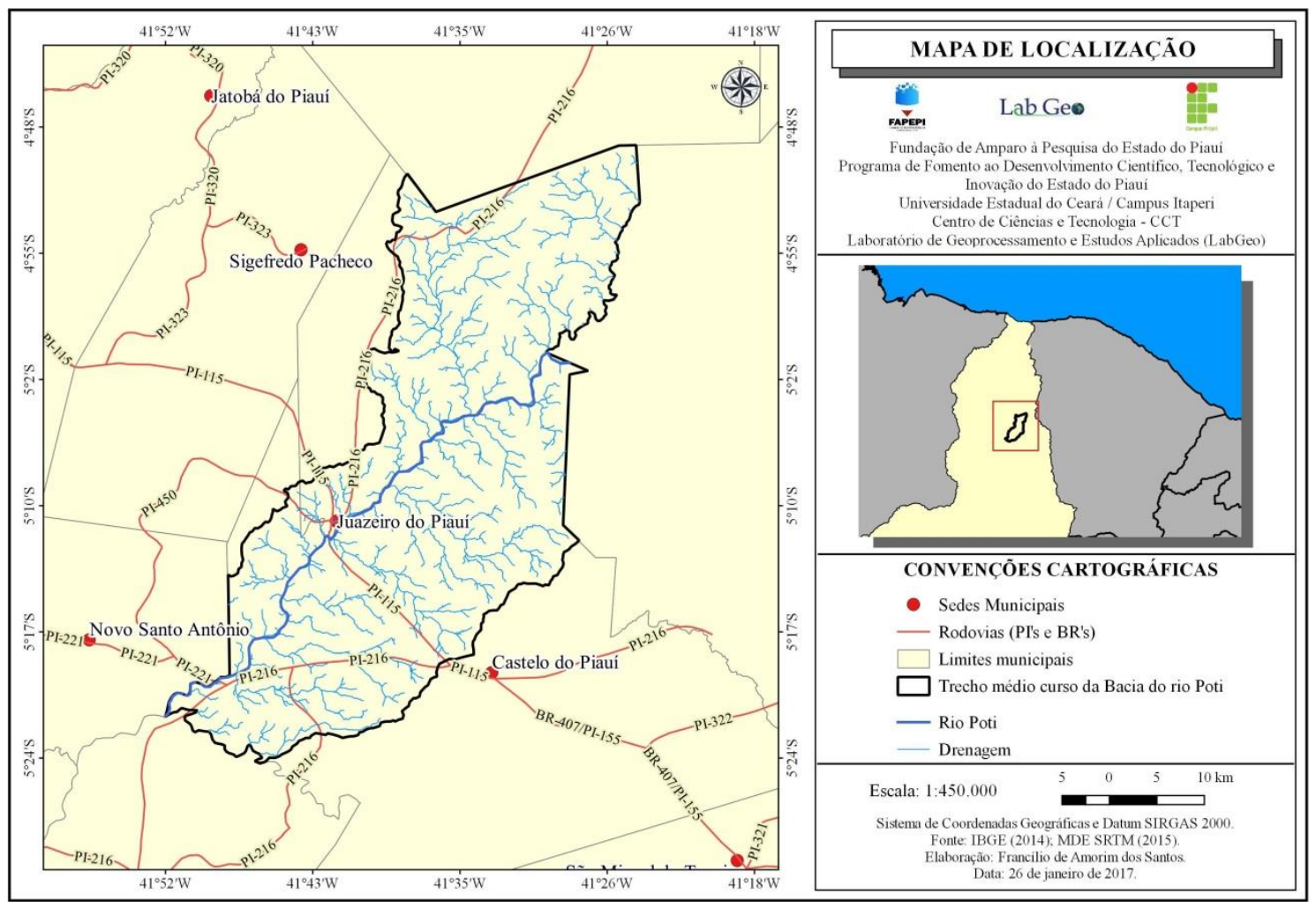

Figura 1 - Localização do trecho do médio curso da Bacia Hidrográfica do rio Poti, obtido via extração de bacias através de dados do MDE SRTM. Fonte: IBGE (2014); USGS (2015).

Inicialmente, realizou-se levantamento de dados de precipitações de 5 (cinco) postos pluviométricos (Figura 2), junto ao site da Agência Nacional de Águas (doravante ANA) (ANA, 2016), considerando uma série histórica de 39 anos, período de 1963 a 2001. Destaca-se que o recorte temporal ocorreu devido às falhas na série histórica após o ano de 2001, para os postos pluviométricos da ANA. 


\section{ANÁLISE DAS PRECIPITAÇÕES EM TRECHO DO MÉDIO CURSO DA BACIA HIDROGRÁFICA DO RIO POTI (PIAUÍ), A PARTIR DO ÍNDICE DE ANOMALIA DE CHUVA (IAC)}

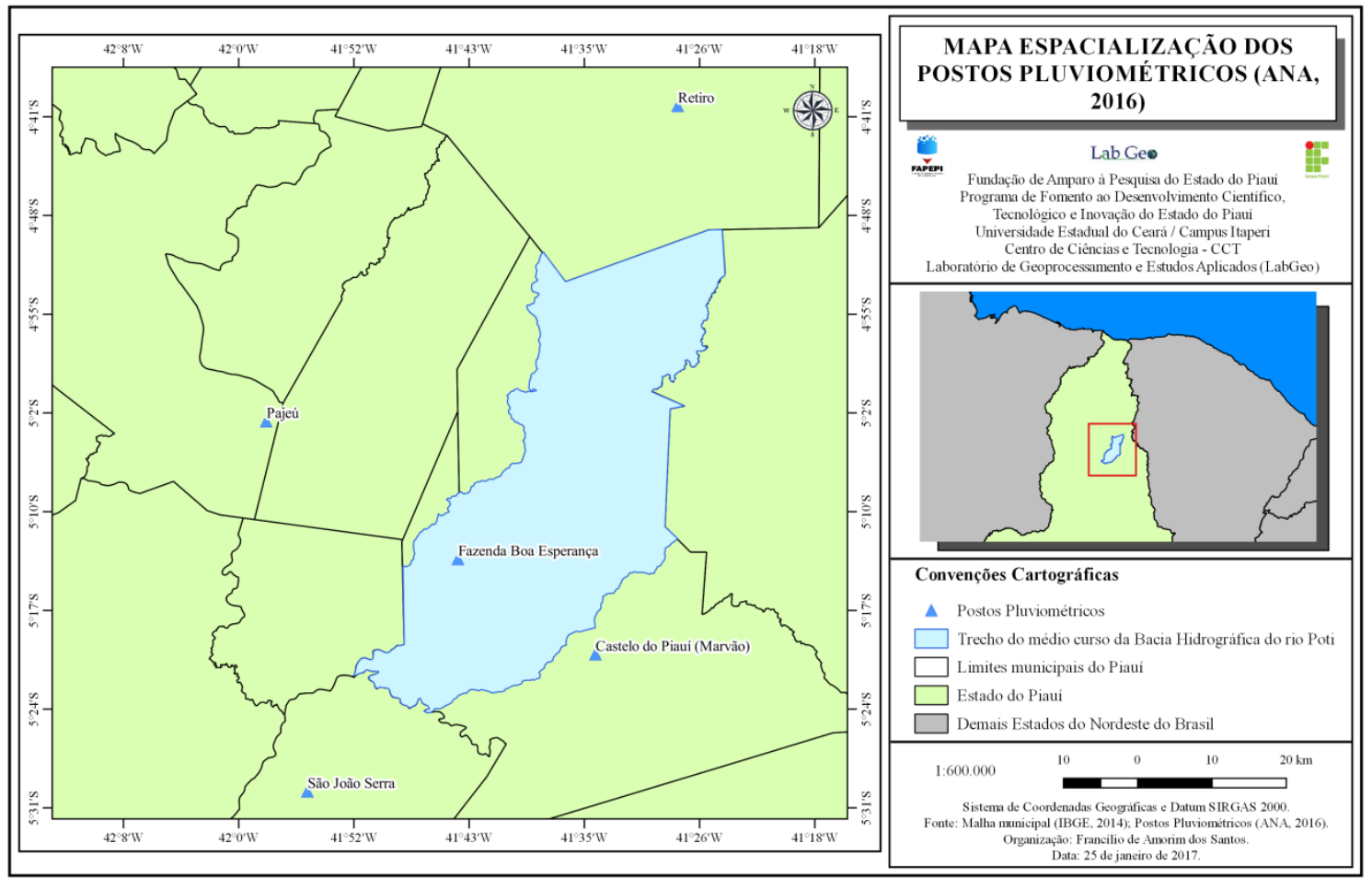

Figura 2 - Espacialização dos postos pluviométricos utilizados para análise da precipitação e dos anos secos e chuvosos do trecho do médio curso da Bacia Hidrográfica do rio Poti. Fonte: ANA (2016).

Em seguida foram realizados procedimentos para correção das falhas da série histórica dos postos pluviométricos por meio do programa FALHAS. Esse se trata de um integrante do pacote de programas USUAIS, que foi desenvolvido por Oliveira e Sales (2016), da Universidade Federal do Ceará (UFC). Cita-se, ainda, que as falhas foram corrigidas mediante aplicação da técnica de Ponderação Regional proposta por Tucci (1993). Essa técnica considera dados de três postos pluviométricos, referentes à precipitação daquele mês onde ocorreu a falha e a precipitação média na série histórica correspondente ao mês cujo dado se deseja preencher (Figura 3).

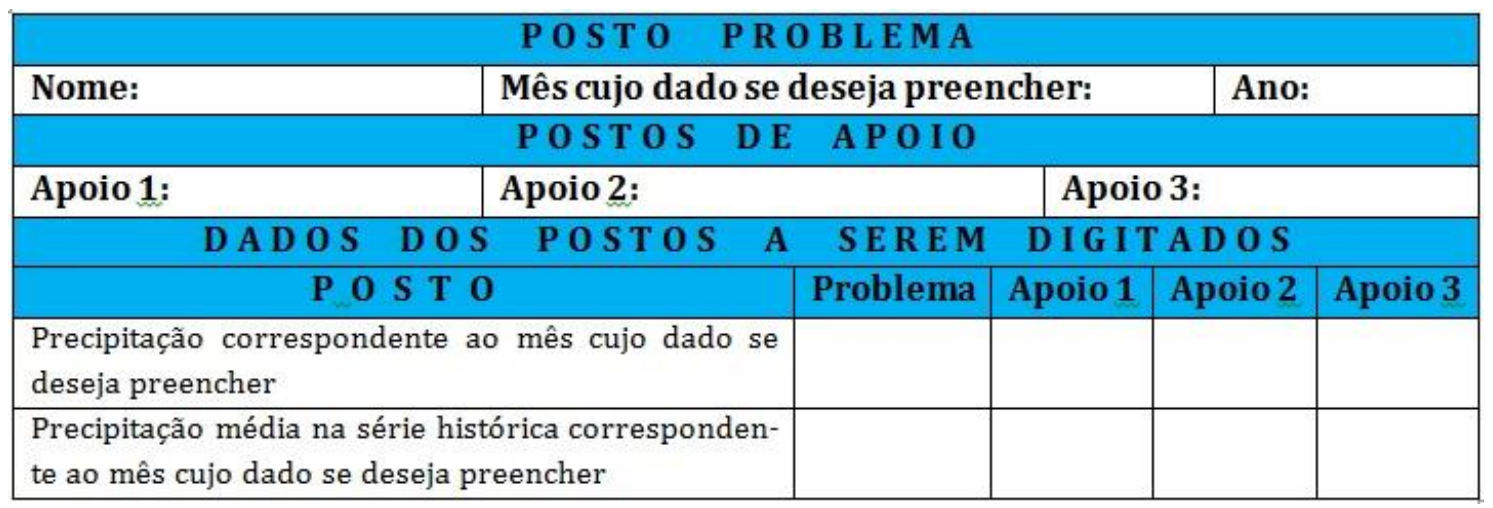

Figura 3 - Quadro para ajuda na correção das falhas do banco de dados pluviométricos. Fonte: Tucci (1993).

Para a realização da estatística descritiva, utilizou-se o software BioEstat, versão 5.0, que é disponibilizado gratuitamente no site do Instituto Mamirauá. Esse software possibilita aplicar fórmulas e testes estatísticos e gerar tabelas e gráficos para interpretação. A 


\section{ANÁLISE DAS PRECIPITAÇÕES EM TRECHO DO MÉDIO CURSO DA BACIA HIDROGRÁFICA DO RIO POTI (PIAUÍ), A PARTIR DO ÍNDICE DE ANOMALIA DE CHUVA (IAC)}

pesquisa considerou os seguintes parâmetros estatísticos: máximo, mínimo, mediana, média, desvio padrão, Coeficiente de variação (Cv), Coeficiente de assimetria (Cas) e Coeficiente de curtose (Ck).

Foram adquiridos dados relacionado ao fenômeno El niño Oscilação-Sul (ENOS), por meio do Climate Prediction Center (CCP - Centro de Previsão Climática). Nesse sentido, considerou-se o Oceanic Niño Index (ONI) para identificação dos fenômenos El Niño e La Niña, respectivamente, $\geq 0,5$ e $\leq$ a $-0,5$. Os ENOS ( $E$ I niño e La niña) podem ser classificados quanto à intensidade em: fracos (valores entre 0,5 a 0,9), moderados $(1,0$ a 1,4$)$ e fortes $(\geq 1,5)$.

Em relação ao Índice de Anomalia da Chuva (IAC), foram utilizados os dados pluviométricos da ANA (2016). Estes, por sua vez, foram tabulados em planilhas eletrônicas e organizados de modo que fosse possível obter a média e o total de precipitação anual para cada posto. Na sequência, foi aplicado aos dados as Equações 1 e 2, conforme proposta metodológica de Rooy (1965) adaptada para o Nordeste do Brasil por Freitas (2004; 2005).
Equação 01

IAC $=3\left[\frac{(N-\bar{N})}{(\bar{M}-\bar{N})}\right]$, para anomalias positivas

Equação 02

$I A C=-3\left[\frac{(N-\bar{N})}{(\bar{X}-\bar{N})}\right]$, para anomalias negativas

Onde:

$N=$ precipitação anual (mm);

$\bar{N}=$ precipitação média anual da série histórica $(\mathrm{mm})$;

$\bar{M}=$ média das 10 maiores precipitações anuais da série histórica $(\mathrm{mm})$;

$\bar{X}=$ média das 10 menores precipitações anuais da série histórica $(\mathrm{mm})$

Tomando como base as Equações acima, foi possível identificar a intensidade dos extremos de anos secos e chuvosos para a área estudada. Destaca-se que as anomalias positivas são aquelas situadas acima da média histórica e as anomalias negativas, aquelas localizadas abaixo da média histórica. Os anos secos e chuvosos extremos foram classificados em 6 (seis) categorias, conforme é apresentado no quadro 1.

\begin{tabular}{|c|c|}
\hline Faixa do IAC & Categorias de Intensidade \\
\hline Acima de 4 & Extremamente Chuvoso (EC) \\
\hline 2 a 4 & Muito Chuvoso (MC) \\
\hline 0 a 2 & Chuvoso (C) \\
\hline 0 a -2 & Seco (S) \\
\hline-2 a -4 & Muito seco (MS) \\
\hline Abaixo de -4 & Extremamente Seco (ES) \\
\hline
\end{tabular}

Quadro 2 - Classes de Intensidade dos anos secos e chuvosos do trecho do médio curso da Bacia Hidrográfica do rio Poti, conforme Índice de Anomalia de Chuva (IAC). Fonte: Freitas (2004; 2005).

Os dados tabelados referentes ao IAC foram utilizados para operacionalização da Geoestatística, baseando-se em 5 (cinco) postos pluviométricos da ANA (2016). A espacialização desses dados foi executada no Sistema de Informação Geográfica (SIG) QuantumGIS (QGIS), versão 2.18, e uso da técnica de interpolação IDW (peso pelo inverso da distância), a partir das classes de intensidade dos anos secos e chuvosos.

\section{RESULTADOS E DISCUSSÃO}

A distribuição anual média das precipitações para o trecho do médio curso da Bacia Hidrográfica do rio Poti, para o período de 1963 a 2001, indicou média histórica de 949,8 $\mathrm{mm}$ anuais, considerando-se a mediana (Figura 


\section{ANÁLISE DAS PRECIPITAÇÕES EM TRECHO DO MÉDIO CURSO DA BACIA HIDROGRÁFICA DO RIO POTI (PIAUÍ), A PARTIR DO ÍNDICE DE ANOMALIA DE CHUVA (IAC)}

4). Observa-se que os anos de 1964, 1974 e 1985 destacam-se por exibir volume pluviométrico acima da média. Ressalta-se ainda que, no ano de 1985, verificou-se o maior valor de precipitação, com aproximadamente 221,2\% acima da média.

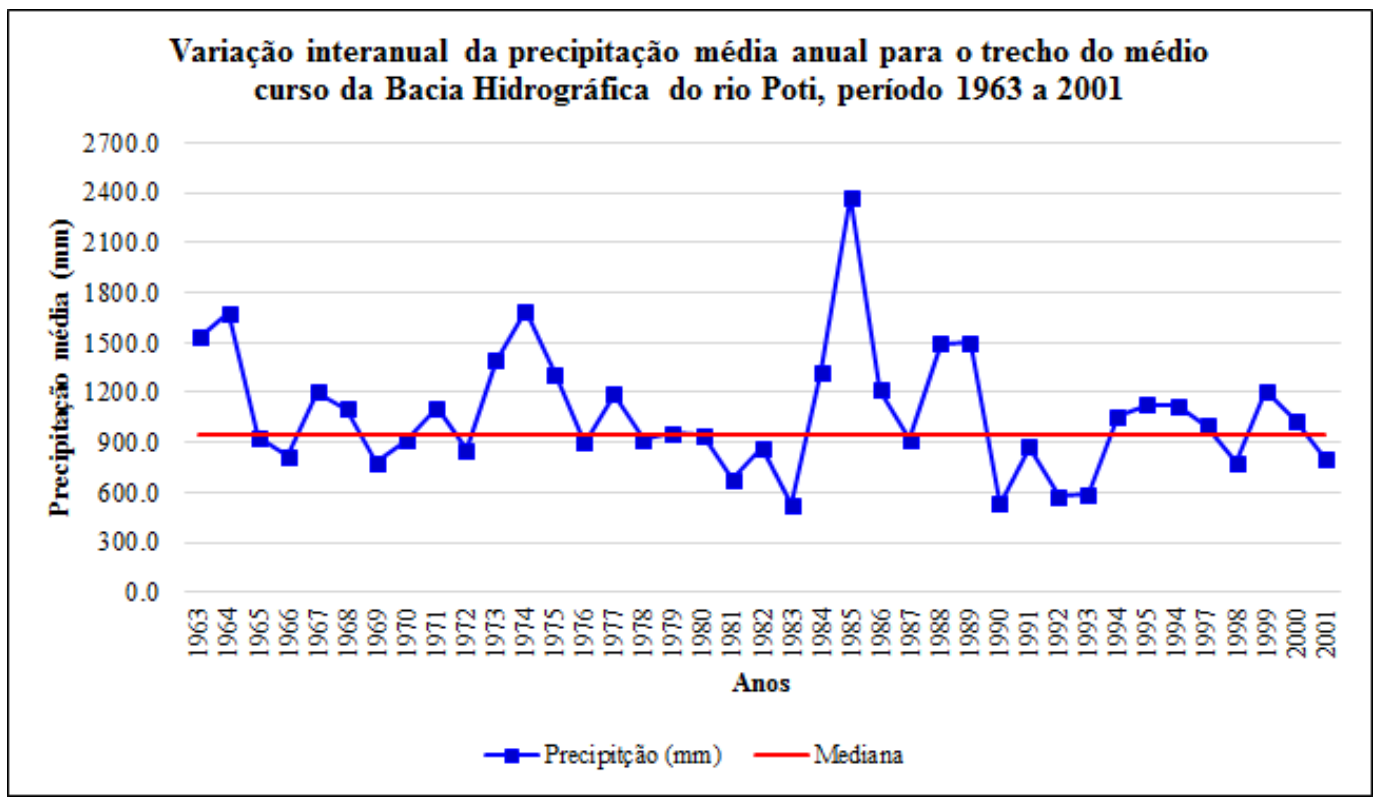

Figura 4 - Variação interanual da precipitação anual média para o trecho do médio curso da Bacia Hidrográfica do rio Poti, período 1963 a 2001. (Mediana =949,8 mm).

Da série histórica analisada, ocorreram dezoito anos com valores de precipitação abaixo da média, corroborando a ideia da irregular distribuição interanual de chuvas para a região. Podem-se destacar dois períodos secos, quais sejam: 1980 a 1983 e 1990 a 1993. Nesse sentido, sobressaem-se os anos de 1983 e 1990, nos quais se podem observar valores de precipitação bem abaixo da média, com redução de aproximadamente $49 \%$ em relação à média da série histórica para o período analisado. Esses dois períodos secos estão ligados à manifestação de fenômenos El niños, que serão discutidos adiante.

O estudo de Sena et al. (2014), para a região do Cariri Paraibano, considerando o período entre 1979 e 2013, apresentou resultados análogos quanto à variação interanual da precipitação. Ao utilizarem a técnica dos quantis, identificaram que o ano de 1985 foi o mais chuvoso, enquanto os anos de
1993 e 1998 apresentaram totais de precipitação abaixo da média histórica, com valores inferiores a $38 \%$ da média. Cita-se, ainda, os resultados do estudo de Silva et al. (2015), para o município de Caruaru (PE) no período de 1969 a 2013, que indicou o ano de 1993 como o de menor ocorrência de chuvas.

No quadro 2, são apresentados os elementos analisados por meio da estatística descritiva, a partir dos dados de precipitação referente aos postos pluviométricos, para o período de 1963 a 2001 (39 anos). Os meses de janeiro, fevereiro, março e abril foram os que apresentaram maiores médias mensais, podendo ser considerados para fins de delimitação da quadra chuvosa na área em estudo. Por outro lado, os meses de julho, agosto e setembro apresentaram as médias mais baixas, com valores abaixo de $10 \mathrm{~mm}$, ou seja, valores reduzidos de precipitação durante esses meses. 
Cerqueira, et al.

\section{ANÁLISE DAS PRECIPITAÇõES EM TRECHO DO MÉDIO CURSO DA BACIA HIDROGRÁFICA DO RIO POTI (PIAUÍ), A PARTIR DO ÍNDICE DE ANOMALIA DE CHUVA (IAC)}

\begin{tabular}{|c|c|c|c|c|c|c|c|c|c|}
\hline \multirow{2}{*}{ Mês } & \multirow{2}{*}{$\mathbf{n}$} & \multirow{2}{*}{ Média } & \multirow{2}{*}{ Mínimo } & \multirow{2}{*}{ Máximo } & \multirow{2}{*}{ Mediana } & \multicolumn{2}{c|}{$\begin{array}{c}\text { Desvio } \\
\text { Padrão }\end{array}$} & \multicolumn{3}{|c|}{ Coeficientes } \\
\cline { 8 - 10 } & & & & & & \multicolumn{2}{|c|}{ Cas } & Ck \\
\hline Jan & 39 & 156,1 & 4,3 & 477,5 & 144,1 & 84,8 & $54,3 \%$ & 1,43 & 4,41 \\
\hline Fev & 39 & 182,7 & 28,6 & 395,9 & 179,0 & 82,9 & $45,4 \%$ & 0,55 & 0,52 \\
\hline Mar & 39 & 270,0 & 71,3 & 510,0 & 269,6 & 113,2 & $41,9 \%$ & 0,37 & $-0,54$ \\
\hline Abr & 39 & 218,7 & 37,7 & 506,9 & 185,9 & 128,2 & $58,6 \%$ & 0,59 & $-0,64$ \\
\hline Mai & 39 & 78,5 & 0,5 & 218,4 & 43,3 & 65,6 & $83,7 \%$ & 0,59 & $-1,21$ \\
\hline Jun & 39 & 14,0 & 0,0 & 71,4 & 7,9 & 16,9 & $121,2 \%$ & 1,71 & 2,67 \\
\hline Jul & 39 & 6,8 & 0,0 & 51,5 & 2,4 & 10,4 & $153,4 \%$ & 2,63 & 8,40 \\
\hline Ago & 39 & 3,3 & 0,0 & 19,0 & 0,8 & 4,9 & $146,0 \%$ & 1,87 & 3,26 \\
\hline Set & 39 & 6,5 & 0,0 & 28,0 & 4,3 & 7,4 & $114,1 \%$ & 1,43 & 1,54 \\
\hline Out & 39 & 13,6 & 0,0 & 56,4 & 12,1 & 13,9 & $102,1 \%$ & 1,36 & 1,72 \\
\hline Nov & 39 & 39,1 & 0,0 & 126,0 & 39,1 & 27,8 & $71,7 \%$ & 1,06 & 1,68 \\
\hline Dez & 39 & 82,6 & 4,4 & 370,8 & 61,3 & 77,8 & $94,2 \%$ & 2,05 & 4,61 \\
\hline
\end{tabular}

Quadro 2 - Parâmetros estatísticos da precipitação média mensal $(\mathrm{mm})$ dos postos pluviométricos utilizados para análise do trecho do médio curso da Bacia Hidrográfica do rio Poti, período 1963 a 2001. Legenda: $\mathrm{Cv}=$ Coeficiente de variação; Cas = coeficiente de assimetria; $\mathrm{Ck}=$ Coeficiente de curtose.

Ao analisar os pontos mínimos e máximos mensais, é possível destacar que os meses com ausência de precipitação também não atingem grande quantidade em relação ao valor máximo. Dessa forma, podem-se apontar os meses de junho a novembro como aqueles que apresentam ausência de precipitação em alguns anos, durante a série histórica de 1963 a 2001. Ao correlacionar esse resultado com a mediana, evidenciam-se os meses de junho, julho, agosto e setembro com precipitações bem abaixo dos demais meses, pois os meses destacados apresentaram anos com ausência de precipitação. Tal fato é típico do setor norte do NEB, cujos totais de precipitação tendem a reduzir a partir do mês de maio.

Considerando o parâmetro estatístico desvio padrão, foi possível observar que os meses de março e abril são aqueles que apresentam maior desvio em relação à média, visto que são os dois meses com maiores volumes pluviométricos, na média histórica considerada pelo estudo. Em contrapartida, valores baixos de desvio padrão, como nos meses de junho a outubro, demonstram que os dados estão mais próximos da média encontrada em cada mês, ratificando a afirmativa de que os meses de junho a novembro são aqueles com menor precipitação, como concluído anteriormente.

No que diz respeito ao Coeficiente de variação (Cv), os meses de janeiro a abril destacam-se por serem os mais homogêneos em relação à média, indicando que a análise desta feita anteriormente pode ser considerada confiável. Ao analisar o Coeficiente de assimetria (Cas), foi possível constatar que todos os meses possuem distribuição assimétrica positiva, uma vez que os valores das médias de precipitação foram superiores aos da mediana.

No que diz respeito ao Coeficiente de curtose (Ck), constatou-se que os meses de março, abril, maio e junho apresentaram valores negativos, indicando uma distribuição de frequência com curva mais fechada, ou seja, leptocúrtica, indicando que as precipitações se apresentam mais bem distribuídas ao longo do mês. Por sua vez, nos meses de janeiro, fevereiro e julho a dezembro, o $\mathrm{Ck}$ positivo indicou uma distribuição platicúrtica, ou seja, curva de frequência mais aberta, podendo-se inferir que são os meses com maior irregularidade pluviométrica.

Partindo do fato de que a média histórica para o referido trecho estudado foi de $1.071,8 \mathrm{~mm}$ anuais, buscou-se identificar os desvios da precipitação anual na área (Figura 5). Foi possível identificar que a estação chuvosa concentra-se entre os meses de janeiro a abril, sendo o mês de março o mais chuvoso, enquanto os meses de maio a dezembro estiveram abaixo da média. Agosto, todavia, apresenta-se como o mês mais seco da série histórica analisada. 


\section{ANÁLISE DAS PRECIPITAÇÕES EM TRECHO DO MÉDIO CURSO DA BACIA HIDROGRÁFICA DO RIO POTI (PIAUÍ), A PARTIR DO ÍNDICE DE ANOMALIA DE CHUVA (IAC)}

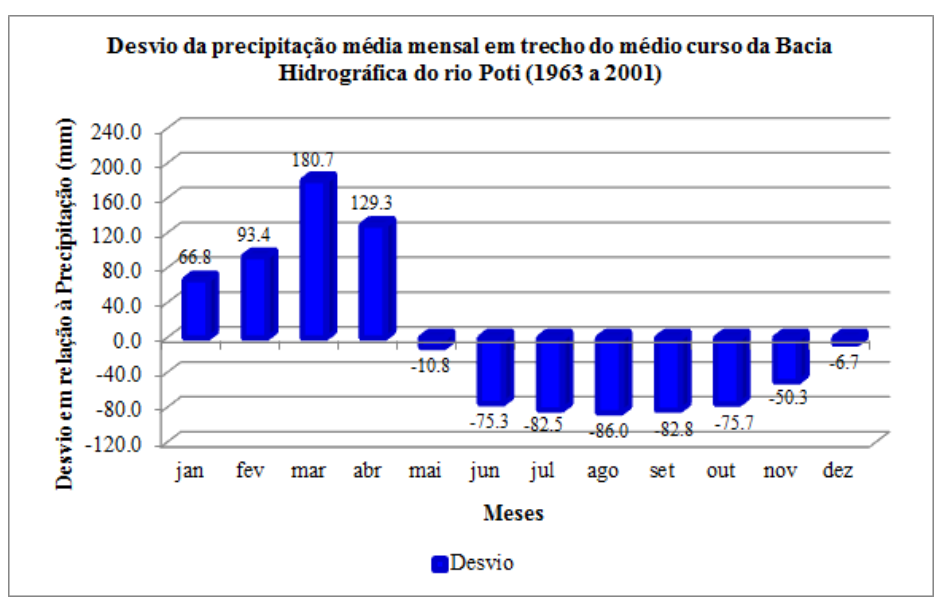

Figura 5 - Desvio da precipitação média mensal do trecho do médio curso da Bacia Hidrográfica do rio Poti, período 1963 a 2001. Fonte: Os autores (2017).

Moura e Jardim (2016) analisaram a tendência e a variabilidade das chuvas no município de Januária (MG). Por meio dos resultados, foi possível inferir que os desvios da precipitação mensal apresentaram a maioria dos meses como secos, ou seja, com índices menores que a média da série histórica. Podese, então, afirmar que há grande variação das precipitações, não se restringindo às condições encontradas no NEB.

Assis et al. (2015) promoveram um estudo da precipitação para o Submédio da bacia do rio São Francisco, a partir do Índice de Anomalia de Chuva. O resultado, também, indicou tendência à diminuição dos totais pluviométricos, que se tornou mais frequente a partir da década de 1980. Tal fato sugere a ocorrência de um ponto de inversão entre a primeira e a segunda metade da série histórica, predominando os anos secos.

\subsection{Análise do Índice de Anomalia da Chuva (IAC) \\ Os resultados obtidos por meio do} Índice de Anomalia das Chuvas (IAC) permitiram analisar sua intensidade para a série histórica de 1963 a 2001 (Figura 6). A análise dessa figura possibilita inferir que o ano de 1985 pode ser classificado como extremamente chuvoso, por possuir IAC com valor de 8,1. Os anos de 1983 e 1990 destacam-se como sendo extremamente secos, já que ambos apresentam IAC com valor de -4,3. Logo, o IAC permitiu inferir que a maioria dos anos analisados foi classificada como seca.

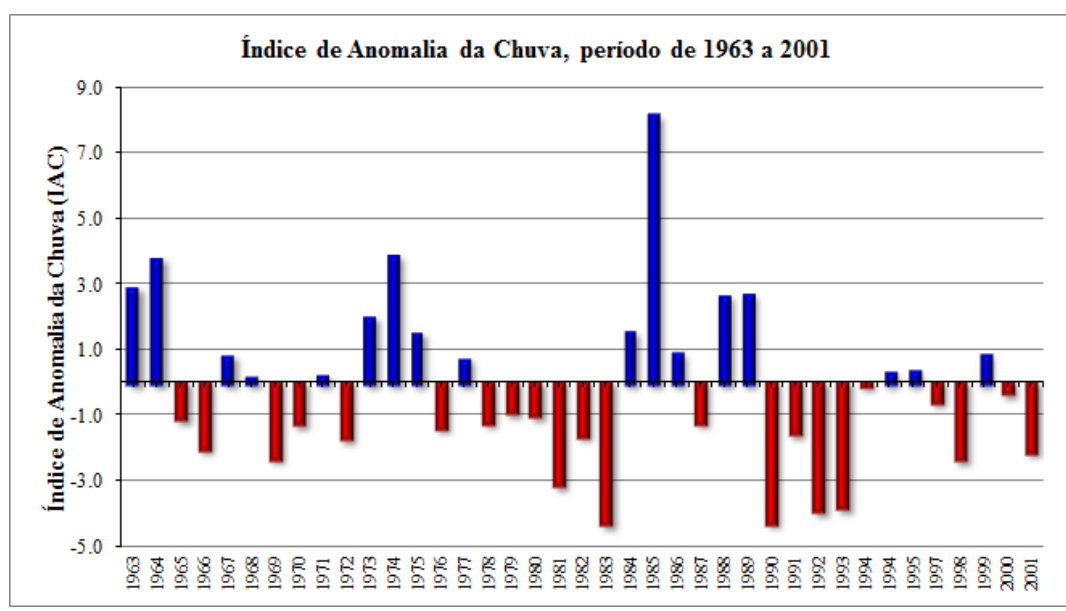

Figura 6 - Desvio da precipitação média mensal do trecho do médio curso da Bacia Hidrográfica do rio Poti, período 1963 a 2001. Fonte: Os autores (2017). 


\section{ANÁLISE DAS PRECIPITAÇÕES EM TRECHO DO MÉDIO CURSO DA BACIA HIDROGRÁFICA DO RIO POTI (PIAUÍ), A PARTIR DO ÍNDICE DE ANOMALIA DE CHUVA (IAC)}

Correlacionando-se os resultados do Quadro 3, observa-se que os anos com IAC superior a 2,0, apresentaram influência do fenômeno La niña ou são neutros, podendo ser relacionados ao dipolo do atlântico, pois valores situados na referida classe possuem dipolo negativo, sendo favorável às chuvas. Os anos com IAC abaixo de $-2,0$, classificados como muito secos ou extremamente secos, ocorreram em sua maioria com influência de fenômenos $E I$ niño. Tal fato mostra que há influência do referido fenômeno e relaciona-se com a fase positiva do dipolo do atlântico, que é desfavorável às chuvas.

\begin{tabular}{|c|c|c|c|c|c|}
\hline Ano & ENOS* & $\begin{array}{l}\text { Dipolo do } \\
\text { Atlântico }\end{array}$ & Ano & ENOS* & $\begin{array}{l}\text { Dipolo do } \\
\text { Atlântico }\end{array}$ \\
\hline 1963 & Neutro & Neutro & 1983 & El niño forte & Positivo \\
\hline 1964 & Neutro & Neutro & 1984 & Neutro & Negativo \\
\hline 1965 & Neutro & Negativo & 1985 & La niña fraca & Negativo \\
\hline 1966 & El niño moderado & Neutro & 1986 & Neutro & Negativo \\
\hline 1967 & Neutro & Negativo & 1987 & El niño moderado & Neutro \\
\hline 1968 & La niña fraca & Neutro & 1988 & La niña fraca & Negativo \\
\hline 1969 & El niño fraco & Neutro & 1989 & La niña moderada & Negativo \\
\hline 1970 & Neutro & Positivo & 1990 & Neutro & Positivo \\
\hline 1971 & La niña moderada & Negativo & 1991 & El niño fraco & Negativo \\
\hline 1972 & Neutro & Negativo & 1992 & El niño forte & Positivo \\
\hline 1973 & El niño moderado & Negativo & 1993 & El niño fraco & Neutro \\
\hline 1974 & La niña forte & Negativo & 1994 & El niño fraco & Negativo \\
\hline 1975 & La niña fraca & Negativo & 1995 & El niño fraco & Negativo \\
\hline 1976 & La niña moderada & Positivo & 1996 & La niña fraca & Negativo \\
\hline 1977 & Neutro & Neutro & 1997 & El niño fraco & Positivo \\
\hline 1978 & El niño fraco & Positivo & 1998 & El niño forte & Positivo \\
\hline 1979 & Neutro & Neutro & 1999 & La niña moderada & Negativo \\
\hline 1980 & El niño fraco & Neutro & 2000 & La niña moderada & Negativo \\
\hline 1981 & Neutro & Positivo & 2001 & La niña fraca & Neutro \\
\hline 1982 & El niño fraco & Positivo & & & \\
\hline
\end{tabular}

Quadro 3 - Fenômenos El niño, La niña e Dipolo do Atlântico (1963 a 2001). *El niño fraco $(0,5$ a 0,9), moderado $(1,0$ a 1,4$)$ e forte $(\geq 1,5)$. Valores negativos para La ninã. Fonte: NOAA (2016).

Obtendo resultados semelhantes, Silva et al. (2010) analisaram a variabilidade da precipitação na Bacia do Rio Tapacurá, situada no estado de Pernambuco, a partir de uma série histórica de 1970 a 2000. A maioria dos anos analisados foi considerada seca, com IAC abaixo da média. O estudo indicou relação das precipitações com os fenômenos La niña e El niño, para anos com IAC bem superior e bem inferior, respectivamente.

A Figura 7 apresenta uma síntese da quantidade de anos secos e chuvosos na área estudada. Desse modo, observa-se o predomínio de anos secos (35,9\%) e chuvosos (25,6\%) na série histórica analisada (1963 a 2001). 


\section{ANÁLISE DAS PRECIPITAÇÕES EM TRECHO DO MÉDIO CURSO DA BACIA HIDROGRÁFICA DO RIO POTI (PIAUÍ), A PARTIR DO ÍNDICE DE ANOMALIA DE CHUVA (IAC)}

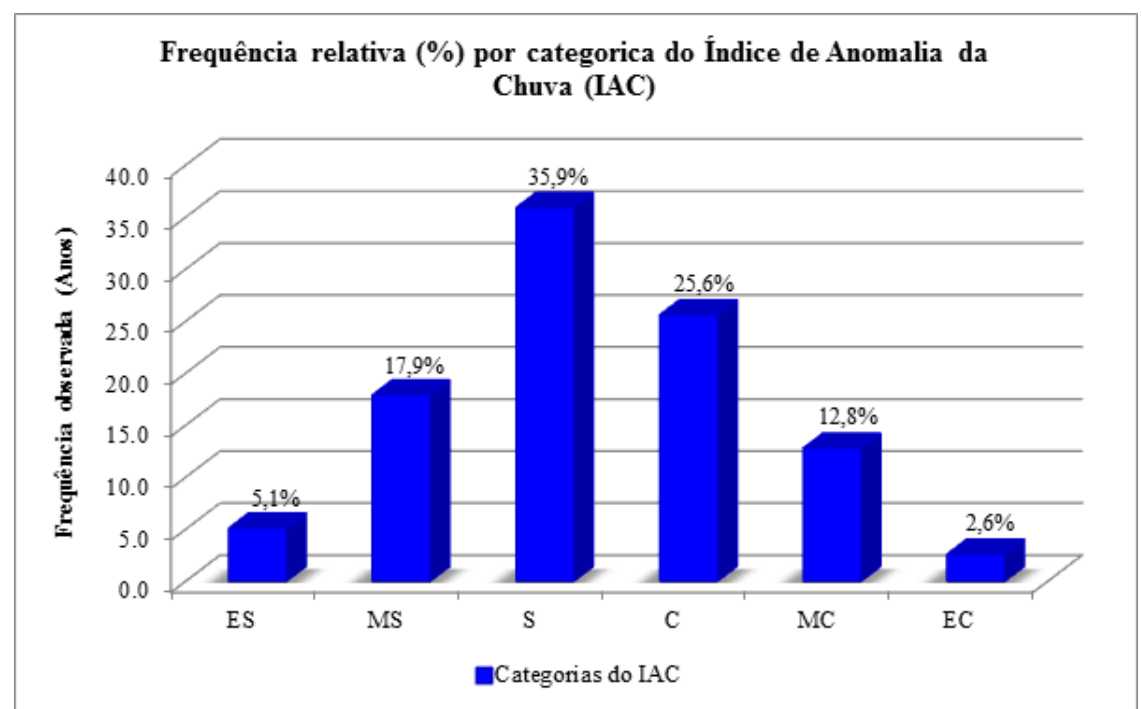

Figura 7 - Frequência relativa (\%) por categoria: Extremamente Seco (ES), Muito Seco (MS), Seco (S), Chuvoso (C), Muito Chuvoso (MC) e Extremamente Chuvoso (EC). Fonte: Os autores (2017).

Os anos muito secos a extremamente secos e os muito a extremamente chuvosos foram registrados em $23 \%$ e $15,4 \%$ da série histórica analisada. Assim, foi possível inferir que há uma maior probabilidade em ocorrer eventos extremos em relação às secas na área de estudo.

\section{CONCLUSÕES}

Por meio do presente estudo foi possível constatar que as precipitações no trecho do médio curso da Bacia Hidrográfica do rio Poti são concentradas e possuem alta variabilidade, considerando a série histórica entre 1963 e 2001. Entretanto, tais resultados corroboram o que se observa na prática em relação à região Nordeste do Brasil (NEB), ou seja, grandes totais pluviométricos concentrados em curto período de tempo, com a maior parte do ano apresentando pluviosidade abaixo da média anual.

A análise pluviométrica via IAC, para o período de 1963 a 2001, permitiu inferir que houve predomínio de anos secos, da ordem de $35,9 \%$, enquanto os anos chuvosos ocorreram em 30,8\% dos anos analisados. Essa dinâmica das precipitações está associada à ocorrência dos fenômenos de ENOS, bem como das fases positivas e negativas do Dipolo do Atlântico.
Ao avaliar a relação dos meses da série histórica analisada, concluiu-se que os meses entre junho e novembro são aqueles com menores níveis de precipitações, e, levando em conta os desvios referentes à média do período, constata-se que o período entre janeiro e abril são os mais chuvosos. Fato que ratifica também que os meses entre junho e novembro constituem o período mais seco da série analisada.

A pesquisa realizada comprova a irregularidade interanual das precipitações no Nordeste do Brasil, particularmente na área do trecho do médio curso da Bacia Hidrográfica do rio Poti. Ressalta-se, por fim, que as informações aqui apresentadas destacam a necessidade de estudos mais aprofundados e integrados na área em foco, nos quais se busque compreender o peso e as consequências da dinâmica pluviométrica sobre os sistemas ambientais e, por conseguinte, das atividades humanas.

\section{AGRADECIMENTOS}

Agradecemos à Fundação de Amparo à Pesquisa do Estado do Piauí (FAPEPI), pelo apoio financeiro do projeto de pesquisa, por meio do Programa de Fomento ao Desenvolvimento Científico, Tecnológico e Inovação do Estado do Piauí, ligado ao Edital de Chamada Pública n.o 006/2015. 


\section{ANÁLISE DAS PRECIPITAÇÕES EM TRECHO DO MÉDIO CURSO DA BACIA HIDROGRÁFICA DO RIO POTI (PIAUÍ), A PARTIR DO ÍNDICE DE ANOMALIA DE CHUVA (IAC)}

\section{REFERÊNCIAS}

ANA - Agência Nacional de Águas. Hidro Web Sistema de Informações Hidrológicas. Séries históricas - ano de 1963 a 2001. Disponível em <http://hidroweb.ana.gov.br/>. Acesso em 09 de outubro de 2016.

ARAÚJO, L.E. Análise estatística de chuvas intensas na bacia hidrográfica do rio Paraíba. 2006. Dissertação (Mestrado em Meteorologia) - Universidade Federal de Campina Grande, Campina Grande - PB, 2006.

ARAÚJO, L.E.; MORAES NETO, J.M.; SOUSA, F.A.S. Analise climática da bacia do rio Paraíbaíndice de anomalia de chuva (IAC). Engenharia Ambiental: Pesquisa e Tecnologia, v. 6, n. 3, 2009.

ARAÚJO, L.E.; SILVA, D.F.; MORAES NETO, J.M.; SOUSA, F.A.S. Análise da variabilidade espaçotemporal da precipitação na bacia do rio Paraíba usando IAC. Revista de Geografia (Recife), v. 24, n. 1, p. 47-59, 2008.

ASSIS, J.M.O.; SOUZA, W.M.; SOBRAL, M.C.M. Análise climática da precipitação no Submédio da bacia do rio São Francisco a partir do Índice de Anomalia de Chuva. Revista Brasileira de Ciências Ambientais, Rio de Janeiro, RJ, n. 36, Junho de 2015.

FREITAS, A.R.; CARVALHO, S.M. A precipitação no município de Irati (PR) entre 1980 e 2015 e sua associação com eventos extremos. XII Simpósio Brasileiro de Climatologia Geográfica. Goiânia-GO, 2016.

FREITAS, M.A.S. A Previsão de Secas e a Gestão Hidroenergética: O Caso da Bacia do Rio Parnaíba no Nordeste do Brasil. In: Seminário Internacional sobre Represas y Operación de Embalses, 2004, Puerto Iguazú: CACIER, v. 1, 2004.

Um Sistema de Suporte à Decisão para o Monitoramento de Secas Meteorológicas em Regiões SemiÁridas. Revista Tecnologia, Fortaleza, p. 84-95, 2005.

IBGE - Instituto Brasileiro de Geografia e Estatística. Cidades. Disponível em <www.cidades.ibge.gov.br>. Acesso em 11 de outubro de 2016.

Malha municipal digital do Brasil: situação em 2014. Rio de Janeiro: IBGE, 2014.
Disponível em: <ftp://geoftp.ibge.gov.br/malhas digitais/>.

Acesso em 04 de abril de 2016.

MOURA, F.P.; JARDIM, C.H. Tendência e variabilidade das chuvas em Januária - MG. XII Simpósio Brasileiro de Climatologia Geográfica. Goiânia-GO, 2016.

NERY, J.T.; FACHINI, M.P.; TANAKA, L.K; PAIOLA, L.M.; MARTINS, M.L.O.F.; BARRETO, L.E.G.S.; TANAKA, I. Caracterização das precipitações pluviométricas mensais para os Estados de Alagoas, Pernambuco e Sergipe. Acta Scientiarum. Technology, v. 20, p. 515-522, 2008.

MONTEIRO, J.B. Chover, mas chover de mansinho: desastres naturais e chuvas extremas no Estado do Ceará. Dissertação (Mestrado em Geografia) - Programa de PósGraduação em Geografia (ProPGeo) / Universidade Estadual do Ceará. Fortaleza, 2011. 198f.

NOAA - National Oceanic and Atmospheric Administration. Climate Prediction Center. Historical El Nino / La Nina episodes (19632001). Disponível em <http://www.cpc.ncep.noaa.gov/products/anal ysis monitoring/ensostuff/ensoyears.shtml>. Acesso em 28 de outubro de 2016.

NÓBREGA, R.S.; SANTIAGO, G.A.C.F.; SOARES, D.B. Tendências do controle climático oceânico sob a variabilidade temporal da precipitação no Nordeste do Brasil. Revista Brasileira de Climatologia, Ano 12, vol. 18, jan/jun, 2016.

OLIVEIRA, J.G.B.; SALES, M.C.L. Usuais: programas para uso em análise ambiental. Revista Equador (UFPI), Vol. 5, n. 2, p.36-60, Janeiro/Junho, 2016.

PIAUÍ. Gabinete do Governador. Palácio de Karnak. Projeto de Lei Complementar no 004, de 14 de fevereiro de 2006. Estabelece o Planejamento Participativo Territorial para o Desenvolvimento Sustentável do estado do Piauí e dá outras providências. 2006.

ROOY, M.P.V. A Rainfall Anomaly Index Independent of Time and Space, Notes, 14, 43, 1965.

SANTOS, F.A. Mapeamento das unidades geoambientais e estudo do risco de 


\section{ANÁLISE DAS PRECIPITAÇÕES EM TRECHO DO MÉDIO CURSO DA BACIA HIDROGRÁFICA DO RIO POTI (PIAUÍ), A PARTIR DO ÍNDICE DE ANOMALIA DE CHUVA (IAC)}

degradação/desertificação nos municípios de Castelo do Piauí e Juazeiro do Piauí. Dissertação (Mestrado em Geografia) - Programa de PósGraduação em Geografia (PPGGEO) / Universidade Federal do Piauí. 2015.

SENA, J.P.O.; MELO, J.S.; LUCENA, D.B.; MELO, E.C.S. Caracterização da precipitação na microrregião do Cariri paraibano por meio da técnica dos quantis. Revista Brasileira de Geografia Física, v. 7, n. 05, p. 1-9, 2014.

SILVA, D.F.; KAYANO, M.T.; SOUSA, F.A.S. Escalas temporais da variabilidade pluviométrica da bacia hidrográfica do rio Mundaú ( $\mathrm{AL}$ e PE). Revista Brasileira de Meteorologia, v. 25, n. 3, 2010.

SILVA, D.F.; SOUSA, F.A.S.; KAYANO, M.T. Uso de IAC e ondeletas para análise da influência das multi-escalas temporais na precipitação da bacia do Rio Mundaú. Revista de Engenharia Ambiental, v. 6, n. 1, p. 180-195, 2009.

SILVA, L.L.; COSTA, R.F.; CAMPOS, J.H.B.C.; DANTAS, R.T. Influência das precipitações na produtividade agrícola no Estado da Paraíba. Rev. bras. eng. agríc. ambient., v. 13, n. 4, 2009.

SILVA, R.M.; SILVA, L.P.; MONTENEGRO, S.M.G.L.; SANTOS, C.A.G. Análise da variabilidade espaço-temporal e identificação do padrão da precipitação na Bacia do Rio Tapacurá, Pernambuco. Revista Sociedade \& Natureza, v. 22, n. 2, 2010.

SILVA, T.F.; PAIVA, A.L.R.; SANTOS, S.M. Análise estatística e tendência das precipitações no município de Caruaru-Pe. XXI Simpósio Brasileiro de Recursos Hídricos. Brasília - DF, 2015.

TUCCI, C.E.M. Hidrologia: ciência e aplicação. Porto Alegre: Eds. da UFRGS e da USP, 1993.

USGS - United States Geological Service (Serviço Geológico dos Estados Unidos). Earth Explorer Digital Elevation - SRTM 1 Arc-Second Global. 2015. Disponível em <http://earthexplorer.usgs.gov/>. Acesso em 23 de novembro de 2015. 